\title{
Contribution of F-Actin to Barrier Properties of the Blood-Joint Pathway
}

\author{
A. POLI, P.J. COLEMAN, R.M. MASON,* AND J.R. LEVICK \\ Department of Physiology, St George's Hospital Medical School, London. UK: \\ *Division of Biomedical Sciences, Faculty of Medicine, Imperial \\ College, London, UK
}

\begin{abstract}
Objectives: Because fibroblast filamentous actin (F-actin) influences cutaneous interstitial matrix swelling pressure (5), we investigated whether F-actin in fibroblast-derived synoviocytes influences the hydraulic permeability of the transsynovial interstitial pathway. The study also tested whether F-actin in fenestrated synovial endothelium contributes to the blood-joint barrier in vivo.

Methods: The clearance of Evans blue-albumin (EVA) from plasma into the knee joint cavity was determined in joint infused with F-actin disrupting cytochalasin D (1-200 $\mu \mathrm{M})$, latrunculin B (100 $\mu \mathrm{M})$ or vehicle in anesthetized rabbits. The hydraulic permeability of the lining was determined as the slope relating net trans-synovial flow $\dot{Q}_{s}$ to intra-articular pressure $P_{j}$. Synovium was examined histologically after i.v. Monastral blue to assess endothelial leakiness.

Results: EVA permeation in vivo was increased up to 25 -fold by cytochalasin ( $p$ $=0.0002$, ANOVA), with an $\mathrm{EC}_{50}$ of $23 \mu \mathrm{M}(95 \%$ confidence limits 13-43 $\mu \mathrm{M})$. Washout quickly reversed the increase. Latrunculin had a similar effect. F-actin disruption switched $\dot{Q}_{s}$ from drainage (control) to filtration into the cavity at low $P_{j}$ in vivo and raised the conductance $d \dot{Q}_{s} / d P_{j}$ by $2.13(p=0.001$, ANOVA). Circulatory arrest abolished these effects. Monastral blue revealed
\end{abstract} numerous endothelial leaks.

Conclusions: F-actin is crucial to the barrier function of fenestrated endothelium in situ. No significant effect of synoviocyte F-actin on matrix permeability was detected.

Microcirculation (2002) 9, 419-430. doi:10.1038/sj.mn.7800149

KEY WORDS: cytochalasin, latrunculin, actin, endothelial permeability, synovium

\section{INTRODUCTION}

Synovium is a sheet of vascular tissue that generates, encapsulates, and drains the synovial fluid of joints. The fluid is generated by a network of fenestrated capillaries just below the synovial surface, which itself comprises a discontinuous layer of synoviocytes and macrophages (14). The fenestrated endothelium has a reflection coefficient of $\geq 0.78$ for plasma albumin (25), and a low-protein ultrafiltrate of plasma trickles slowly into the joint cavity when sy-

Supported by Wellcome Grant 056983/Z99 and European Community TMR Grant ERBFMRXCT980219.

For reprints of this article, contact J.R. Levick, Department of Physiology, St. George's Hospital Medical School, London, UK: e-mail: (secretary)etown@sghms.ac.uk

Received 23 January 2002; accepted 24 April 2002 novial fluid pressure is low, as in extended joints. When synovial fluid pressure is raised by flexion, the net trans-synovial inflow ceases, and intra-articular fluid is driven out through drainage channels between the discontinuous lining cells into the subsynovial lymphatic system. The drainage pathway has a high hydraulic resistance due to the presence of hyaluronan, sulfated proteoglycans, fibronectin, and collagens I, III, IV, V, and VI (32).

The hydraulic resistance of a matrix depends on its hydration (6). Reed, Rubin, and colleagues have shown that in rat skin and tracheal mucosa the matrix hydration and interstitial fluid pressure are influenced actively by the filamentous actin (F-actin) cytoskeleton of fibroblasts $(5,43)$. F-actin is present in synoviocytes and endothelium, linking the cells to the extracellular matrix through $\beta_{1}$ integrins (49) and hyaluronan receptors $(26,28)$. In addition, a pe- 
ripheral $\mathrm{F}$-actin ring in endothelium serves as an anchor for intercellular junctional proteins (12). In light of the above facts, the work of Reed's group raised the issue of whether synovial F-actin might influence fluid and macromolecular dynamics in joints.

Specifically, the findings of Reed, Rubin, and colleagues indicated that fibroblast $\mathrm{F}$-actin exerts tension on interstitial collagen through $\alpha_{2} \beta_{1}$-integrins and thereby opposes the interstitial glycosaminoglycan swelling pressure. Disruption of the equilibrium by antibody to $\alpha_{2} \beta_{1}$-integrin or by the actin filament-disrupting agent cytochalasin caused interstitial pressure to fall to a more subatmospheric pressure during $\sim 30$ minutes because of the unopposed gel-swelling pressure. This was best demonstrated post mortem. In vivo, interstitial pressure fell to a lesser degree, and the hydration and albumin content of the tissue increased, indicating that F-actin disruption raises endothelial permeability (5). Studies in vitro support this; in endothelial monolayers, cytochalasin disrupts the microfilaments, raises permeability, and causes cell retraction and gap formation $(1,19,22,46)$. Changes in $\mathrm{F}$-actin distribution also occur in venular endothelium during inflammation $(3,15)$. Intravascular cytochalasin causes edema, a fall in the albumin reflection coefficient, and a rise in the microvascular filtration capacity in vivo, $(16,27,46)$.

The above findings raise two questions concerning fluid transport in joints. First, does endothelial Factin influence the resistance of fenestrated endothelium to fluid and macromolecule permeation? (The above studies were conducted on continuous endothelium.) Second, because synoviocytes are closely related to fibroblasts (14) and have cytoskeletal linkage to synovial extracellular matrix components through integrins (45) and CD44 (2,20), does synoviocyte $\mathrm{F}$-actin influence extracellular hydration and hence the permeability of the extracellular pathway?

The above questions were addressed by experiments using two F-actin-disrupting drugs, cytochalasin and latrunculin. Cytochalasin D is a fungal metabolite that disrupts the actin cytoskeleton in minutes, primarily by capping the barbed or growing end of the actin filament. The actin filament is a dynamic structure that turns over at a rate of $>4.5 \mu \mathrm{m} \mathrm{min}{ }^{-1}$ because of the continuous removal of monomeric Gactin at one end and its addition at the opposite end (48). Blockage of the growing end of the filament by cytochalasin is quickly followed by filament disas- sembly in endothelium (52) and fibroblasts (44). Latrunculin B is a Red Sea sponge toxin that inhibits F-actin polymerization by binding to the cytosolic pool of G-actin, reducing its availability and causing rapid filament disruption $(11,47)$.

The present study examines the effects of F-actindisrupting agents on three parameters: the clearance of labeled protein from plasma into the joint cavity; Monastral blue permeation through endothelium; and synovial matrix conductivity. The study extends a recent investigation of changes in intra-articular pressure and matrix interstitial pressure following F-actin disruption (40). The latter investigation indicated that actin disassembly raised capillary filtration rate and $\gamma$-globulin permeation, but that synoviocyte F-actin disassembly had no detectable effect on interstitial fluid pressure post mortem, in contrast to the findings of Berg et al. (5) in rat skin.

\section{METHODS}

\section{Overview}

Experiments were based on an established rabbit knee model. After an i.v. injection of Evans bluetagged albumin (EVA) into the plasma compartment, the joint cavity was cannulated and vehicle with or without the F-actin-disrupting drug was injected intra-articularly. After 30 minutes, the joint fluid was sampled and a second intra-articular cannula was introduced. One cannula was connected to a pressure transducer and the other to a raised fluid reservoir and drop counter. The reservoir raised the joint pressure $P_{j}$ so that the relation between $P_{j}$ and net trans-synovial flow $\dot{Q}_{s}$ could be determined. Intra-articular EVA was washed out every 15 minutes to assess permeation across the blood-joint barrier. The two key parameters studied were thus $C l_{E V A}$ (clearance of Evans blue-albumin from synovial plasma into joint cavity) and $d \dot{Q}_{s} / d P_{j}$ (the hydraulic conductance of the synovial lining). In addition, endothelial leakage was assessed histologically by the Monastral blue method. The experiment was usually repeated on the contralateral joint by using plain vehicle or a low dose of drug.

\section{Experimental Preparation and Determination of $d \dot{Q}_{s} / d P_{j}$}

New Zealand white rabbits weighing $2.5-3 \mathrm{~kg}$ were anesthetized with $30 \mathrm{mg} \mathrm{kg}^{-1}$ sodium pentobarbitone plus $500 \mathrm{mg} \mathrm{kg}^{-1}$ urethane i.v. and tracheostomized. Anesthesia was maintained at sufficient depth to abolish the corneal blink reflex by using i.v. $15 \mathrm{mg}$ of sodium pentobarbitone plus $250 \mathrm{mg}$ of 
urethane every 30 minutes. Procedures conformed to UK animal legislation, and animals were killed by an overdose of i.v. sodium pentobarbitone at the end of the experiment.

The intra-articular infusion and recording systems were as described by Coleman et al. (10). A single cannula was inserted initially into the joint cavity to deliver a bolus of $150-400 \mu \mathrm{L}$ of test solution. After 30 minutes, the intra-articular fluid was aspirated and a second intra-articular cannula was inserted and connected to an infusion reservoir. The height of the reservoir "clamped" $P_{j}$ at any desired level. Flow from the infusion reservoir into the joint cavity, $\dot{Q}_{i n}$, was recorded by a photoelectric drop counter. Because of the high cost of the drugs, only the terminal $10 \mathrm{~mL}$ of the infusion system was filled with drugcontaining solution. An inverted-U air gap separated the test solution from the drop counter fluid. The latter was a $0.1 \% \mathrm{v} / \mathrm{v}$ solution of chlorhexidine (Hibitane; ICI, Macclesfield, UK), which reduced surface tension to generate a drop of $6 \mu \mathrm{L}$. A step elevation of the infusion reservoir caused a transient inrush of test fluid into the joint as the cavity expanded and then $P_{j}$ stabilized and flow reached a steady state within 15 minutes $(10,29)$.

Flows were measured at the end of each 15-minute period at pressures of $\sim 2.5,5.0$, and $7.5 \mathrm{cmH}_{2} \mathrm{O}$ (below yield pressure) to estimate the physiological conductance of the joint lining and then at $\sim 12,16$, and $20 \mathrm{cmH}_{2} \mathrm{O}$ (corresponding to taut effusions) to estimate the raised conductances that develop above the yield pressure of the synovial lining $(13,29)$. Net trans-synovial drainage rate $\dot{Q}_{s}$ was calculated from $\dot{Q}_{i n}$ at the end of each period by subtracting a small correction for the viscoelastic creep of the cavity walls as described previously $(10,29)$.

With high concentrations of drug, the net transsynovial flow reversed direction at low intraarticular pressures. Because a net trans-synovial flow into the joint cavity halted the flow through the drop counter, $\dot{Q}_{s}$ was calculated as the rate of rise of pressure $d P_{j} / d t$ multiplied by the corresponding mean joint compliance, taken from Knight and Levick (23).

\section{Macromolecular Flux and Synovial Plasma Clearance, $C l_{E V A}$}

A 10-mL injection of EVA was given through the ear vein at the start of the experiment $(10 \mathrm{mM}$ of Evans blue with $120 \mathrm{mg} \mathrm{ml}^{-1}$ bovine serum albumin in Ringer's solution). Dye is $>99 \%$ bound in this mixture because of its high-affinity coefficient (31).
Plasma samples were obtained by centrifugation of venous blood taken at 30 minutes and the end, 270 minutes. At the end of the first 30 minutes of exposure to drug and after each subsequent 15 minutes infusion period, the intra-articular fluid was aspirated and weighed. The EVA content of the aspirates and plasma was determined densitometrically from the light absorbance of $200 \mu \mathrm{L}$ samples in a multiwell plate transilluminated by white light by using a Fluor-S multi-imager and Quantity One Quantitation Software (Biorad Laboratories Ltd., Hemel Hempstead, UK) to analyze gray-scale images.

The flux of EVA from synovial plasma into the joint cavity, $d \mathrm{~m} / d t$, was calculated as the cumulative sum of all the aspirated EVA masses (concentration $x$ aspirated volume) divided by time. A small correction was added for the unaspirated EVA mass in the residual intra-articular fluid after the final aspiration. Residual volume was estimated as the intraarticular volume at the final pressure (taken from the joint compliance curve) (32) minus the final aspirated volume. Small corrections were also added for the trans-synovial convection of EVA out of the joint cavity during each 15-minute interval between aspirations; the washed-out mass was calculated as $\dot{Q}_{s} \times 15 \times$ mean intra-articular concentration (average of start and end concentrations). The above two corrections were small and did not materially change the result. Plasma clearance was calculated as $(\mathrm{dm} /$ $d t) / C_{p}$, where $C_{p}$ is mean plasma concentration during the experiment. The plasma concentration fell by $\sim 5 \%$ per hour, so $C_{p}$ was approximated as the arithmetical average of the 30-minute and 270-minute concentrations.

\section{Demonstration of Endothelial Leakage Sites Using Monastral Blue}

The Monastral blue method (21) was used to test whether cytochalasin D causes endothelial gap formation in vivo. After an initial intra-articular injection of cytochalasin $\mathrm{D}(100 \mu \mathrm{M}), d P_{j} / d t$ was monitored for 30 minutes to confirm that the drug had taken effect. A volume of $2.5 \mathrm{~mL}$ of $3 \%$ particulate Monastral Blue BF suspension (copper phthalocyanine, CI 74160) was then injected into the ear vein, and cytochalasin D was infused continuously into the joint cavity at $5.6 \mathrm{cmH}_{2} \mathrm{O}$. After 1 hour, the animal was killed, and 6\% paraformaldehyde solution was perfused through the joint cavity for 30 minutes. The partially fixed joint lining was excised, and control samples were taken from the contralateral joint. Excised tissue was fixed for 48 hours in paraformaldehyde and transferred 
to glycerine for 48 hours. Initial examination through a dissecting microscope using epiillumination and low magnification indicated dye leakage but had poor optical resolution. To improve the optical conditions sheets of synovium were microdissected off the specimen, washed in Ringer's solution, dehydrated through a graded ethanol series, and clarified for 24 hours in methylsalicylate. Clarified sheets were mounted en face for examination by transillumination by using a Zeiss microscope at $x 80$ to $x 320$. Four sheets of synovium from two rabbits were examined. In another two animals, the synovial tissue was embedded in Spurr resin and unstained, semi-thin sections ( $\sim 1 \mu \mathrm{m}$ thick) were cut for light microscopy.

\section{Intra-Articular Half-Life of Small, Diffusible Solutes}

The intra-articular concentration of a small, rapidly diffusible solute such as cytochalasin D (508 Da) decays continuously in vivo because of clearance by the microcirculation. The intra-articular half-lives of solutes of size 370-582 Da are 14-24 minutes (40). Partly for this reason and partly to obtain samples, the joint was aspirated as completely as possible every 15 minutes and refilled with fresh solution. The fall in intra-articular drug concentration was thus limited to $\sim 1 / 2$ nominal concentration before the next top-up.

\section{Materials}

Cytochalasin D and latrunculin B were purchased from Calbiochem (Nottingham, UK). Monastral Blue, bovine serum albumin, dyes, phosphatebuffered saline, and $\alpha_{2}$-macroglobulin (see below) were from Sigma Chemical Co. (Poole, UK). Cytochalasin D (1 mg) was dissolved in $0.5 \mathrm{~mL}$ of dimethyl sulfoxide (DMSO), which was then added drop by drop to phosphate-buffered saline at $\mathrm{pH} 7.4$ with continuous rapid stirring to prevent precipitation, until the required concentration was reached. The control solutions, referred to as "vehicle," contained the same concentration of DMSO as the contralateral test solution (maximum 5\% DMSO). Therefore, differences in response were attributable to the drug, not DMSO. The infused drug concentrations were $0,1,10,25,50,100$, and $200 \mu \mathrm{M}$ of cytochalasin D and $100 \mu \mathrm{M}$ of latrunculin B. DMSO was not required to dissolve the latrunculin.

The broad-spectrum protease inhibitor $\alpha_{2}$ macroglobulin was included in one experiment with $200 \mu \mathrm{M}$ of cytochalasin D to determine whether tissue protease activation played a role $(50)$. The amount of $\alpha_{2}$-macroglobulin used, namely, $1 \mathrm{mg}$ in $10 \mathrm{~mL}$ of $200 \mu \mathrm{M}$ of cytochalasin D, was sufficient to inhibit $>10 \mu \mathrm{g}$ of trypsin activity or $10^{4}$ BAEE units per mg protein.

\section{Statistical Methods}

Results were compared by using Student's t test or analysis of variance (ANOVA) as appropriate, with $p$ $\leq 0.05$ considered a significant difference. To facilitate comparison of flows at identical pressures (because $P_{j}$ varied a little between experiments), flows were interpolated to standard pressures by linear interpolation between the two bounding measurements. Slopes were fitted to pressure-flow relations by linear regression analysis. $\mathrm{EC}_{50}$ was estimated by fitting a four-parameter logistic equation (top, bottom, Hill slope, $\mathrm{EC}_{50}$; GraphPad Prism, San Diego, CA) to the logarithmic dose-response curve. Means and slopes are followed by their standard errors throughout.

\section{RESULTS}

\section{Permeation of EVA from Plasma into the Joint Cavity}

It was obvious from the washout color that the permeation of labeled plasma albumin into the joint was increased greatly by cytochalasin D. Samples from joint cavities infused with control solution were almost colorless, whereas samples from joints infused with $\geq 25 \mu \mathrm{M}$ cytochalasin $\mathrm{D}$ were blue (dye concentration $>20 \mu \mathrm{M})$. Even the first aspirate, after only 30 minutes of exposure to drug, was blue, indicating a rapid breakdown of the endothelial barrier. The increased EVA permeation was maintained throughout the 2-hour experiment.

In control joints the flux of EVA into the joint cavity averaged $5.1 \pm 1.8 \mathrm{nmol} \mathrm{h}^{-1}(n=8)$. Because the plasma EVA concentration varied between rabbits, the fluxes were normalized by plasma concentration to calculate synovial plasma clearance (see Methods). The control clearance was $6.2 \pm 1.4 \mu \mathrm{L} \mathrm{h}^{-1}$ $(n=8)$.

Cytochalasin D at $200 \mu \mathrm{M}$, the highest concentration investigated, increased the EVA flux approximately 25 -fold to $126.3 \pm 34.5 \mathrm{nmol} \mathrm{h}^{-1}$ and raised the synovial plasma clearance to $167.0 \pm 34.5 \mu \mathrm{L} \mathrm{h}^{-1}(n$ $=4)$. Clearance increased as a sigmoidal function of the logarithm of concentration as illustrated in Fig. 1 $(p=0.0002$, one-way ANOVA). All cytochalasin concentrations of $50 \mu \mathrm{M}$ or above raised the clearance significantly above control $(p<0.05$, Bonfer- 


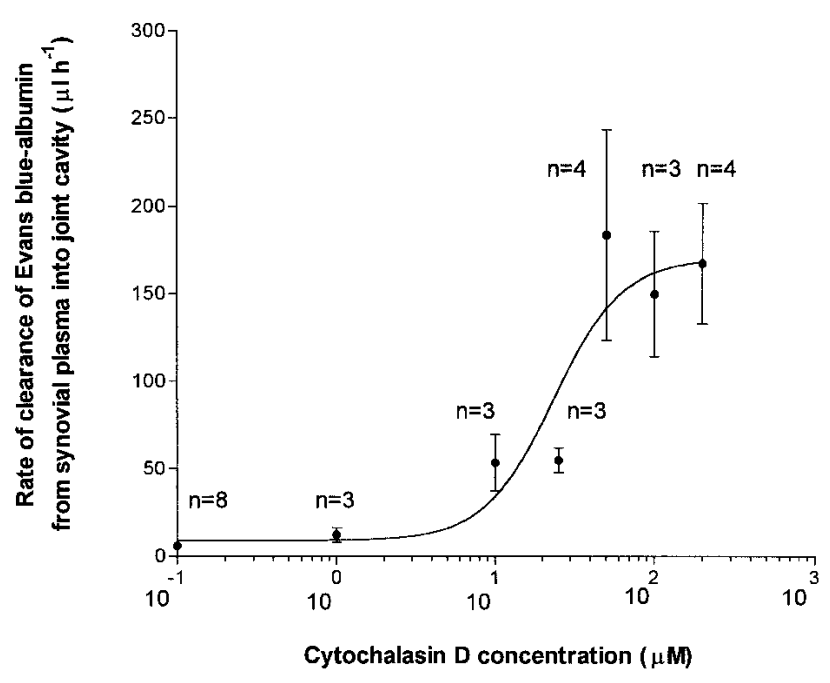

Figure 1. Permeation of Evans blue-labeled plasma albumin into the joint cavity, expressed as plasma clearance, as function of cytochalasin D concentration (mean \pm SEM). The result for vehicle alone is plotted at $10^{-1} \mu \mathrm{M}$ cytochalasin on the logarithmic scale. The fitted curve $\left(\mathrm{EC}_{50}=23 \mu \mathrm{M}\right)$ is described in Statistical Methods.

roni's post hoc test). The estimated $\mathrm{EC}_{50}$ was $23 \mu \mathrm{M}$, with $95 \%$ confidence interval (CI) of $13-43 \mu \mathrm{M}$.

Although cytochalasin is known to act directly on endothelial cells (see Introduction), we also tested whether protease activation might contribute to the observed changes. Inclusion of the broad-spectrum protease inhibitor $\alpha_{2}$-macroglobulin (see Methods) had no discernible effect however. Cytochalasin D with $\alpha_{2}$-macroglobulin raised the EVÁ clearance to $185 \mu \mathrm{L} \mathrm{h}^{-1}$, which is $\sim 30$ times the control value. The effect of cytochalasin D on hydraulic conductance, described below, was likewise unaffected by $\alpha_{2}$-macroglobulin.

\section{Fractional Extraction of Synovial Plasma EVA}

The fractional extraction of albumin during the transit of plasma through the synovial microcirculation was estimated as the EVA clearance divided by the synovial plasma flow, which was taken to be 45-90 $\mu \mathrm{L} \mathrm{min}^{-1}$ (40). The extraction of EVA across normal synovial endothelium (mean clearance 6.2 $\mu \mathrm{L} \mathrm{h}^{-1}$, or $0.10 \mu \mathrm{L} \mathrm{min}{ }^{-1}$ ) was $0.1-0.2 \%$. This is similar to the extraction of radiolabeled albumin from the human circulation $(\sim 0.08 \%)(38)$. The low extraction indicates that, despite its fenestrations, synovial endothelium has only a low basal permeability to plasma protein. This is in accord with its high albumin reflection coefficient, $\geq 0.78$ (25). The extraction increased to $3.1-6.2 \%$ after treatment with $200 \mu \mathrm{M}$ of cytochalasin.

\section{Effect of Cytochalasin D on the Synovial Pressure-Flow Relation In Vivo}

The pressure-flow relation for saline across the normal synovial lining is usually approximated by two straight lines, one fitted below $9 \mathrm{cmH}_{2} \mathrm{O}$ (yield pressure) and the other above it $(13,29)$. Cytochalasin treatment changed both the intercept and the slope of the relation during the low-pressure range but had no significant effect at higher pressures (Fig. 2).

Effect on Intercept. Cytochalasin D treatment reversed the direction of the net trans-synovial flow at low pressures. The increased filtration into the joint cavity shifted the intercept of the regression line with the y-axis (net trans-synovial flow) at zero (atmospheric) pressure in a negative direction. The shift was $-12.9 \mu \mathrm{L} \mathrm{min}{ }^{-1}$ in response to $100-200 \mu \mathrm{M}$ cytochalasin D $(n=6)$. The intercept shift was a function of cytochalasin concentration $(p<0.001$, one-way ANOVA) and was statistically significant at concentrations of $\geq 50 \mu \mathrm{M}(p<0.05$, Bonferroni's post hoc test). The sigmoidal relation between inter-

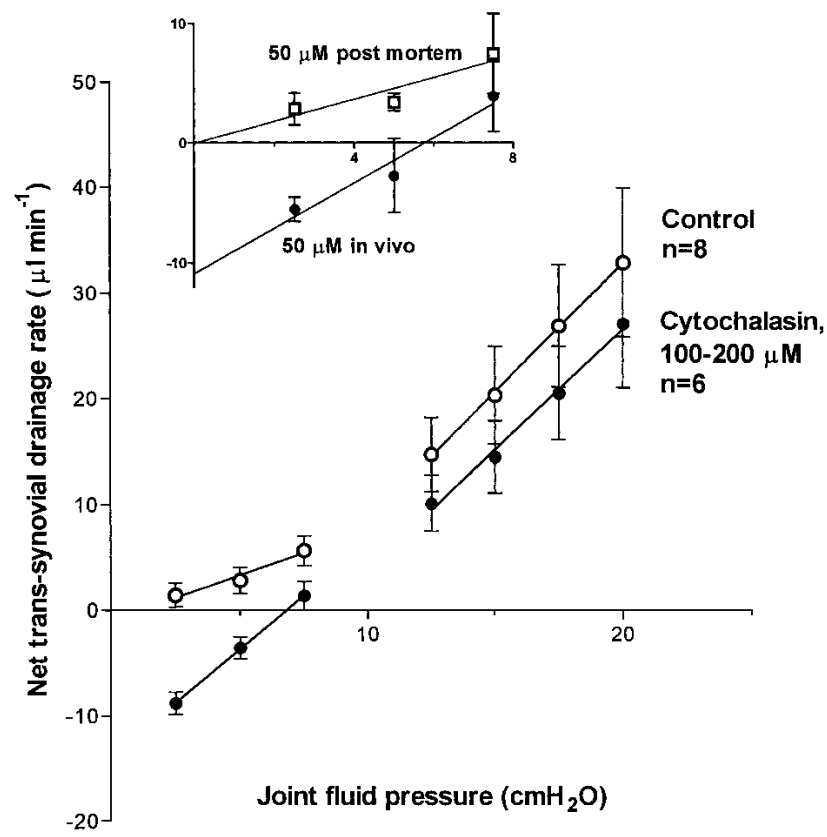

Figure 2. Effect of 50-200 $\mu \mathrm{M}$ cytochalasin D on relation between net trans-synovial flow and joint fluid pressure. Negative flows denote net filtration into the cavity. Open circles, vehicle alone $(n=8$; mean \pm SEM $)$; the relation steepens above $\sim 9 \mathrm{cmH}_{2} \mathrm{O}$ (yield pressure) and is fitted by two regression lines (see text). Filled circles, cytochalasin $\mathrm{D}(n=6)$; at low intra-articular pressures cytochalasin D reversed the flow and steepened the relation. Inset, effect of $50 \mu \mathrm{M}$ of cytochalasin D in vivo and post mortem. Circulatory arrest abrogates the effect of intra-articular drug on trans-synovial flow and conductance. 
cept and the logarithm of concentration indicated an $\mathrm{EC}_{50}$ of $25.7 \mu \mathrm{M}$, with $95 \%$ CI of $16.3-40.6 \mu \mathrm{M}$ (concentrations $0,1,10,25,50,100$, and $200 \mu \mathrm{M}$, corresponding $n=8,3,2,3,4,3,3)$. Cytochalasin had no significant effect on the intercept of regression lines fitted to results above yield pressure $(p=$ 0.65 , one-way ANOVA).

Effect on Slope. Cytochalasin treatment increased the slope $d \dot{Q}_{s} / d P_{j}$ during the low-pressure range, indicating that the hydraulic permeability of the endothelial and/or synovial interstitial pathway had been raised (Fig. 2). The slope was a function of the cytochalasin concentration $(p=0.0014$, oneway ANOVA), and the sigmoidal relation between the slope and the logarithm of concentration indicated an $\mathrm{EC}_{50}$ of $17 \mu \mathrm{M}$. The slope more than doubled in response to 100-200 $\mu \mathrm{M}$ cytochalasin, from $0.87 \pm 0.22 \mu \mathrm{L} \mathrm{min}{ }^{-1} \mathrm{cmH}_{2} \mathrm{O}^{-1}$ (control, $n=$ 8) to $1.86 \pm 0.11 \mu \mathrm{L} \mathrm{min}{ }^{-1} \mathrm{cmH}_{2} \mathrm{O}^{-1}(n=6)$. Cytochalasin did not increase the slope above yield pressure (control, $2.33 \pm 0.05 \mu \mathrm{L} \mathrm{min}^{-1} \mathrm{cmH}_{2} \mathrm{O}^{-1}$, $n=8$; cytochalasin-treated, $2.07 \pm 0.09 \mu \mathrm{L} \mathrm{min}{ }^{-1}$ $\left.\mathrm{cmH}_{2} \mathrm{O}^{-1}, n=6\right)$.

In control joints, $d \dot{Q}_{s} / d P_{j}$ increased 2.7-fold as pressure was raised above yield point; the slope values are given above. Because cytochalasin raised the slope at low pressures $\left(1.86 \pm 0.11 \mu \mathrm{L} \mathrm{min}{ }^{-1}\right.$ $\left.\mathrm{cmH}_{2} \mathrm{O}^{-1}\right)$ but not at high pressures $(2.07 \pm 0.09 \mu \mathrm{L}$ $\left.\mathrm{min}^{-1} \mathrm{cmH}_{2} \mathrm{O}^{-1}\right)$, there was no obvious yield point after cytochalasin treatment.

To assess the contribution of microvascular filtration to the above results, the pressure-flow relation in vivo during cytochalasin infusion was compared with that after cardiac arrest.

\section{Effect of Cytochalasin D on Pressure-Flow Relation After Circulatory Arrest}

In vivo, treatment with $50 \mu \mathrm{M}$ of cytochalasin had the following effects (Fig. 2, inset, lower relation). The average trans-synovial flow at $2.5 \mathrm{cmH}_{2} \mathrm{O}$ reversed direction from a net drainage of $1.39 \pm 1.11$ $\mu \mathrm{L} \min ^{-1}$ ( $n=8$, controls) to a net filtration of -5.6 $\pm 1.0 \mu \mathrm{L} \min ^{-1}(n=4)$. The intercept shifted from $-1.1 \pm 1.0 \mu \mathrm{L} \mathrm{min}{ }^{-1}$ (control) to $-10.9 \pm 2.4 \mu \mathrm{L}$ $\min ^{-1}$; the slope increased 2.3-fold, from $0.87 \pm$ $0.22 \mu \mathrm{L} \mathrm{min}{ }^{-1} \mathrm{cmH}_{2} \mathrm{O}^{-1}$ (control) to $1.96 \pm 0.34$ $\mu \mathrm{L} \min ^{-1} \mathrm{cmH}_{2} \mathrm{O}^{-1}(p<0.05)$.

Circulatory arrest abolished the above responses (Fig. 2, inset, upper relation). Measurements were commenced immediately after the arrest. Circulatory arrest prevented the reversal of net trans- synovial flow by cytochalasin; the trans-synovial drainage rate at $2.5 \mathrm{cmH}_{2} \mathrm{O}$ averaged $+2.86 \mu \mathrm{L}$ $\min ^{-1}(n=2)$. The intercept, $0 \pm 2.2 \mu \mathrm{L} \mathrm{min}^{-1}$, was no longer shifted to a negative value. The slope, 0.68

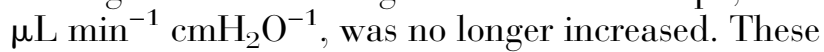
results indicate that the effect of cytochalasin D on trans-synovial flow depends on synovial microvascular perfusion.

\section{Correlation Between Changes in Albumin Permeation and Trans-Synovial Flow}

If cytochalasin acts by increasing the number and/or size of gaps in the endothelial barrier (see later), a correlation may be expected between macromolecule permeation and filtration into the joint. Although the protocol was not ideally suited for testing this issue, there was a highly significant correlation between filtration rate into the cavity at low pressure and EVA clearance into the cavity at $0-200 \mu \mathrm{M}$ of cytochalasin (Fig. 3) (Pearson's $\mathrm{r}=0.72, p<0.0001$ ). The dimensionless slope of the relation, $-0.18 \pm$ 0.03 , indicates that the net filtration of $1 \mu \mathrm{L}$ into the cavity was associated with the clearance of only $0.12-0.24 \mu \mathrm{L}(95 \% \mathrm{CI})$ of plasma EVA into the cavity.

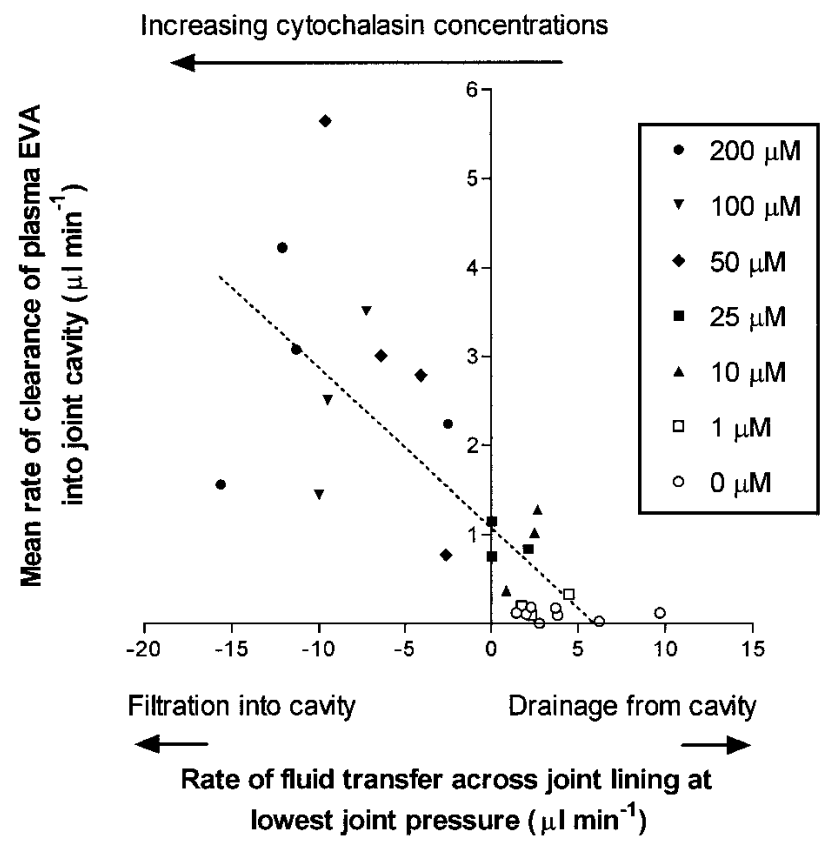

Figure 3. Correlation between the effect of cytochalasin D on trans-synovial flow at low intra-articular pressure and on the mean clearance of plasma Evans blue-albumin into the same joint cavity during the course of the experiment. Dimensionless slope of dashed regression line is $-0.18 \pm 0.03$ ( $n=28$ joints $)$. 


\section{Reversibility of Cytochalasin-Induced} EVA Permeation

After the i.v. injection of EVA, the joint cavity was infused with $50 \mu \mathrm{M}$ of cytochalasin D. The net transsynovial flow was measured at several intra-articular pressures, and fluid was aspirated every 15 minutes to assess EVA influx. The cavity was then washed out three times with $500 \mu \mathrm{L}$ of Ringer's solution, and the flows and EVA fluxes were redetermined with Ringer's solution instead of cytochalasin D in the infusion line. This protocol was followed in two joints.

Figure 4 shows that the effect of cytochalasin on plasma EVA permeation is readily reversed. The $\mathrm{cy}-$ tochalasin D raised the EVA clearance to 196-350 $\mu \mathrm{L} \min ^{-1}$ at $15-45$ minutes. After washout and reinfusion with Ringer's solution, the EVA clearance declined with time, falling to $54 \mu \mathrm{L} \mathrm{min}{ }^{-1}$ by 90 minutes after washout. A similar result was obtained in the second joint.

The washout of the cytochalasin D also changed the direction of net trans-synovial flow from, e.g., a net filtration rate of $-1.7 \mu \mathrm{L} \mathrm{min}^{-1}$ at $5.5 \mathrm{cmH}_{2} \mathrm{O}$ in the presence of cytochalasin to a net drainage rate of $+3.7 \mu \mathrm{L} \mathrm{min}^{-1}$ at $5.3 \mathrm{cmH}_{2} \mathrm{O}$ after washout. Rapid reversibility of the effect of cytochalasin D was likewise reported by Poli et al. (40).

\section{Effects of Latrunculin B on Trans-Synovial Flow and EVA Permeation}

Two studies were conducted by using $100 \mu \mathrm{M}$ of latrunculin B. The effects of latrunculin closely resembled those of cytochalasin. The mean clearance

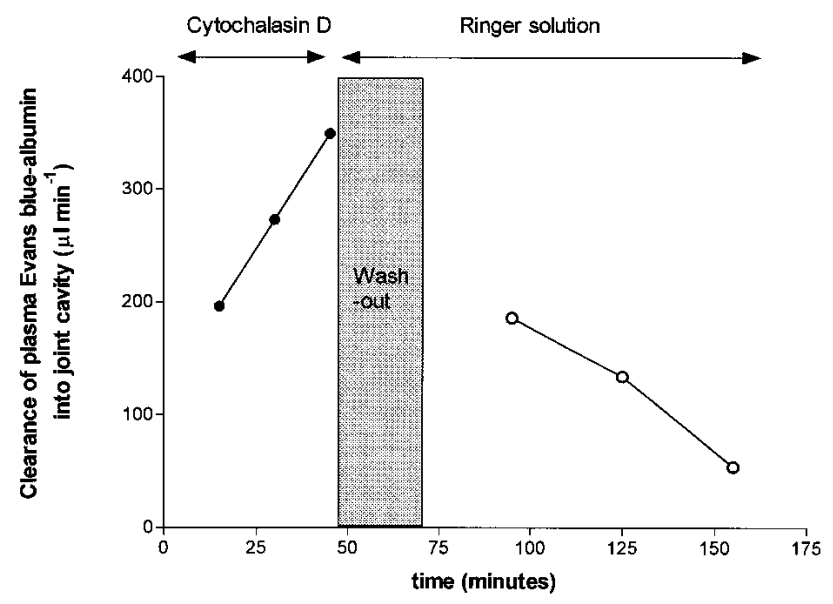

Figure 4. Reversal of the effect of cytochalasin D on permeation of plasma EVA into the joint cavity after drug washout. of EVA into the joint cavity increased by an order of magnitude from $6 \mu \mathrm{L} \mathrm{min}{ }^{-1}$ (control) to $55 \mu \mathrm{L}$ $\min ^{-1}$ and $149 \mu \mathrm{L} \min ^{-1}(n=2)$. Net transsynovial flows at low pressure reversed direction within 3.5-8.0 minutes to net filtrations into the cavity of $-2.5 \mu \mathrm{L} \min ^{-1}$ and $-3.6 \mu \mathrm{L} \min ^{-1}$. The intercept of the pressure-flow relation shifted negatively to $-4.3 \mu \mathrm{L} \mathrm{min}{ }^{-1}$ and $-11.5 \mu \mathrm{L} \mathrm{min}^{-1}$; slopes $d \dot{Q}_{s} / d P_{j}$ in the low-pressure range increased to 1.10

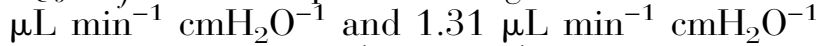
(control $0.83 \mu \mathrm{L} \mathrm{min}^{-1} \mathrm{cmH}_{2} \mathrm{O}^{-1}$ ). The similarity of the effects of latrunculin and cytochalasin D, which disrupt F-actin by different mechanisms, supports the view that the observed changes are mediated specifically through an effect on F-actin.

\section{DMSO Controls}

The similar responses to cytochalasin D solution and latrunculin solution showed that the effects did not depend on a synergism with DMSO; DMSO was not present in the latrunculin solution. The pressureflow relation for control solutions containing DMSO at $0.5-5.0 \%\left(0.77 \pm 0.15 \mu \mathrm{L} \mathrm{min}{ }^{-1} \mathrm{cmH}_{2} \mathrm{O}^{-1}\right)$ was within the range for DMSO-free controls in a previous work (41). There was no significant relation between DMSO in the control solutions during the range $0-5 \%$ and control $d \dot{Q}_{s} / d P_{j}$ (regression $-0.04 \pm$ $0.08 \mu \mathrm{L} \min ^{-1} \mathrm{cmH}_{2} \mathrm{O}^{-1} \%{ }^{-1}, p=0.63, n=8$ ) or between \% DMSO and control EVA clearance (regression slope $-0.05 \pm 0.78 \mu \mathrm{L} \mathrm{h}^{-1} \%^{-1}, p=0.95$, $n=8$ ). Thus, it is unlikely that DMSO influenced the results.

\section{Effect of Cytochalasin D on Monastral Blue Leakage} Through Endothelium

Intravenous Monastral blue did not label normal synovial microvessels significantly. After cytochalasin treatment, abundant spots and streaks of trapped Monastral blue particles were seen in the synovial sheets viewed en face (Fig. 5). The deposits were distributed irregularly along the microvessels and were often elongated, being up to 7-11 $\mu \mathrm{m}$ long by $1-2 \mu \mathrm{m}$ wide. Streaks tended to run obliquely to the longitudinal axis of the vessel and were occasionally forked, which is consistent with the well-known elongated, polyhedral arrangement of endothelial cell margins. Semi-thin transverse sections showed clusters of fine Monastral blue particles at the margins of microvessels. Where vessels were caught in a grazing longitudinal section, rows of particles were often observed, forming linear streaks similar to those seen en face. Leakage was seen chiefly in microvessels of width 7-18 $\mu \mathrm{m}$, tentatively identified 

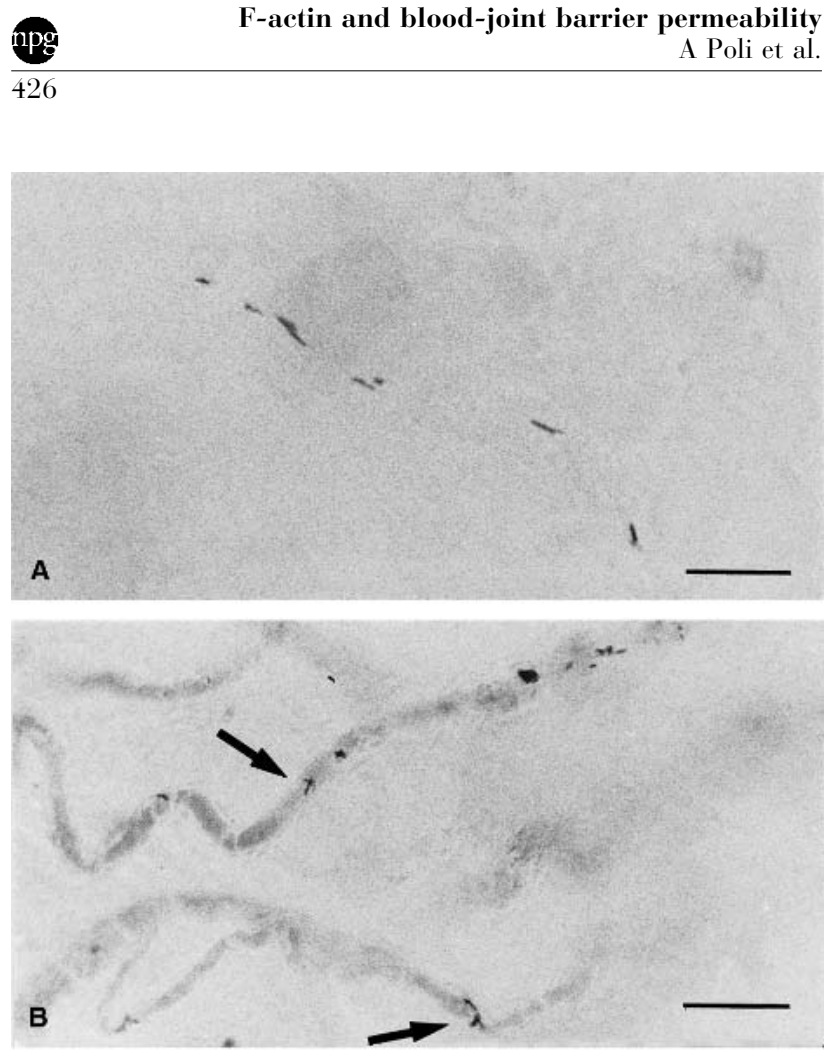

C

Figure 5. Photomicrographs of methylsalicylate-clarified synovium viewed en face, showing endothelial leakage of particulate intravascular Monastral blue after $100 \mu \mathrm{M}$ intra-articular cytochalasin $\mathrm{D}$ in vivo (A and $\mathrm{B}$ ) or no treatment (C). A: Synovial venule with seven Monastral bluedelineated leakage sites. Six of the sites are elongated along the vessel longitudinal axis. Scale bar $=45 \mu \mathrm{m}$. $B$ : Venule with multiple leakage sites. Arrowed deposits are elongated and branched. Scale bar $=30 \mu \mathrm{m}$. C: Untreated synovium from contralateral joint. No Monastral blue deposits are present. Scale bar $=50 \mu \mathrm{m}$.

as postcapillary venules, but was also seen in capillaries as narrow as $5 \mu \mathrm{m}$ diameter.

\section{DISCUSSION}

The principal positive findings were that cytochalasin and latrunculin enhance fluid filtration into a joint cavity and raise the plasma protein permeation $>10$-fold. The EC50 values were larger than those reported in vitro, but this may be due partly to the short intra-articular half-lives of the drugs and partly to phenotype changes in cultured endothelium. The two main questions raised in the Introduction are addressed below.

\section{Does F-Actin Influence the Resistance of Fenestrated Endothelium to Macromolecular and Fluid Exchange In Vivo?}

EVA fluxes are expressed here as clearances rather than permeability because the latter term implies purely diffusional transport, whereas both diffusion and convection contributed to EVA transport in the present study. The "apparent permeability" of the blood-joint barrier, i.e., flux by combined diffusionconvection/concentration difference, was only a few percent higher than the reported plasma clearance because the plasma concentration was more than an order of magnitude higher than the intra-articular concentration. The apparent permeability was increased more than 20 -fold by $200 \mu \mathrm{M}$ of cytochala$\sin \mathrm{D}$.

Because synovial endothelium is the site of reflection of plasma proteins (25) and because the Monastral blue experiments showed that leaks developed in the endothelial layer, it seems reasonable to conclude the increase in the apparent permeability of the bloodjoint pathway originated in the endothelial component.

The correlation between increased albumin flux and increased volume flux (Fig. 3) is attributed to endothelial gap formation, which creates a new, shared pathway for macromolecules and water. The high filtration rate into the joint cavity is attributed to the high conductance of endothelial gaps of $\mu \mathrm{m}$ dimensions, and presumably a large fall in the protein reflection coefficient $\sigma$. The latter would reduce the effective plasma colloid osmotic pressure and thus raise the net Starling filtration force. An increase in net Starling filtration force is evident from the right shift of the intercept with the $x$-axis (joint pressure at zero net trans-synovial flow, Fig. 2); a right shift is the expected effect of an increased net filtration pressure due to a fall in $\sigma$ as indicated by a simplified, one-dimensional model of trans-synovial flow $(25,29)$. The changes, in fact, resemble those during inflammation, in which endothelial intercellular and transcellular gaps up to $1 \mu \mathrm{m}$ wide cause large increases in microvascular filtration rate and plasma protein leakage $(35,37)$.

The slope of the relation in Fig. 3 shows that the clearance of EVA into the joint cavity was substantially less than the volume of fluid filtering into the joint cavity per minute. Possible reasons include the 
non-zero reflection of albumin during filtration through the drug-induced pathway, as in some histamine-treated capillaries $(9,36)$, and the loss of pericapillary EVA into periarticular tissue, particularly when the net trans-synovial flow was outward at >45-60 minutes. Another possibility would be the formation of high conductance but reflective pathways, such as the fenestrations induced by the calcium ionophore A23187 in mesenteric capillaries (8).

\section{Relation Between Filamentous Actin and Endothelial Barrier Integrity}

As reviewed in the Introduction, cytochalasin in vitro causes the breakdown of actin microfilaments, intercellular gap formation, and cell retraction in confluent endothelial cultures. In the present study, endothelial gaps formed in vessels in situ, indicating that actin filaments contribute to the structural integrity of the fenestrated endothelial barrier. This conclusion is in keeping with the view that intercellular junction proteins, such as the cadherin-catenin complex, are restrained spatially by linkage through $\alpha$-actinin to the actin cytoskeleton (12). Other cell lines with a similar junctional biochemistry show a reduction in the number of junctional strands after cytochalasin treatment $(4,34,42)$. Our observations do not exclude the formation of transcellular gaps, as opposed to intercellular gaps (37), or the involvement of vesicular-vacuolar organelles (17).

It is possible, in principle, that the cytochalasin D might act indirectly, e.g., to trigger mast cell degranulation. This seems unlikely to be the major mechanism, however, because cytochalasin D has a powerful, direct effect on isolated endothelium. Moreover, the microvascular hyperpermeability was well maintained for $>2$ hours, whereas the effect of mast cell histamine peaks early (10-20 minutes) and decays rapidly.

\section{Rapidity of Drug Action and Reversal}

The rapid effect of cytochalasin on EVA permeation (Fig. 4) indicates a fast turnover of F-actin in fenestrated endothelium in vivo, in keeping with the fast turnover of $\mathrm{F}$-actin in many cultured cell lines (48). Cytochalasin in vitro can increase the permeability of arterial endothelial monolayers to dextran by fourfold in 30 minutes (22). The reversal of the hyperpermeability state within minutes of drug washout (Fig. 4) indicates a rapid rebuilding of F-actin within the fenestrated endothelial cell in vivo.

\section{Potential Relation Between F-Actin Disruption and Synovial Inflammation}

The combination of order-of-magnitude increases in plasma protein permeation, rapid fluid filtration, and endothelial gap formation reported here closely resembles the acute response to proinflammatory agonists such as histamine, serotonin, bradykinin, and interleukin IL-1 $\beta$. Histamine, serotonin, and bradykinin quickly cause plasma extravasation into the rat knee joint $(7,39)$. Interleukin IL-1 $\beta$ causes large increases in trans-synovial fluid filtration, raised intra-articular pressure, and increased albumin permeation in the equine metacarpophalangeal joint (18). In human synovitis, a breakdown of the endothelial barrier to plasma proteins and water leads to the accumulation of a protein-rich joint effusion (51).

In view of the similarities, it is tempting to suggest that F-actin disruption may be one of the links between agonist receptor activation and gap formation. In support of this, changes in F-actin distribution and disruption of the peripheral $\mathrm{F}$-actin ring are observed in endothelium in response to proinflammatory agonists $(3,15,33)$. By contrast, a popular paradigm for gap formation invokes endothelial contraction through a sliding filament mechanism dependent on the interaction of actin filaments with phosphorylated myosin, a process that seems unlikely to be enhanced by the disruption of F-actin. The possibility that endothelium contains a stable, myosin-associated pool of $\mathrm{F}$-actin and a rapidly turning over, cytochalasin-sensitive pool of cytoskeletal F-actin linked to the junctional proteins would be one possible solution to this paradox.

\section{Does Synoviocyte F-Actin Influence the Permeability of the Extracellular Pathway?}

The other question raised in the Introduction was whether the F-actin cytoskeleton of synoviocytes influences the permeability of the joint lining, through an effect on matrix swelling tendency and hydration analogous to that observed by Berg et al. (5) in rat skin. A partial answer to this question was provided by Poli et al. (40), who found that cytochalasin has no detectable effect on interstitial fluid pressure in the synovial lining. Two findings here reinforce the conclusion that synoviocyte $\mathrm{F}$-actin does not acutely influence the interstitial matrix properties. First, cytochalasin D did not affect hydraulic conductance $d \dot{Q}_{s} / d P_{j}$ above yield pressure. In this pressure range, the net flow is predominantly interstitial, because interstitial permeability increases above yield pressure $(13,30,41)$. Second, when endothelial fluid 
exchange was eliminated by circulatory arrest, cytochalasin likewise failed to raise the hydraulic conductance $d \dot{Q}_{s} / d P_{j}$ at low pressures (Fig. 2, inset). Thus, the results indicate that cytochalasin $\mathrm{D}$ does not increase the conductance of the synovial interstitial pathway either below or above yield pressure.

A potential alternative interpretation of the observations post mortem would be that circulatory arrest itself reduces the interstitial matrix conductance within 15 minutes or so. However, a recent servonull micropipette study showed that the interstitial pressure profile across the joint lining for a given trans-synovial flow post mortem is indistinguishable from that in vivo (45b). This finding indicates that circulatory arrest does not alter the matrix conductance.

In joints with a functionally intact microcirculation, the increase in $d \dot{Q}_{s} / d P_{j}$ induced by cytochalasin is attributed to the reduced resistance of the endothelial component of the series pathway; endothelial resistance is a substantial component, $\sim 50 \%$, of the total resistance to flow between blood and the joint cavity at low intra-articular pressure (24).

In control synovium, the slope $d \dot{Q}_{s} / d P_{j}$ increased nearly threefold above $\sim 9 \mathrm{cmH}_{2} \mathrm{O}$, producing a kink in the pressure-flow plot. This long-recognized phenomenon is caused by increased stretch and hydration of the interstitial matrix $(13,30,41)$. After cytochalasin treatment, the slope at low pressure, $1.86 \pm$ $0.11 \mu \mathrm{L} \mathrm{min}{ }^{-1} \mathrm{cmH}_{2} \mathrm{O}^{-1}$, had increased to a value almost as big as that at high pressures, $2.07 \pm 0.09$ $\mu \mathrm{L} \min ^{-1} \mathrm{cmH}_{2} \mathrm{O}^{-1}$, so a kink in the curve was no longer detectable.

To summarize, the results showed that F-actin in the fenestrated synovial endothelium has a major role in maintaining the normal synovial microvascular barrier to plasma albumin and fluid filtration. The results failed to support the hypothesis that the F-actin in synoviocytes influences the permeability of the synovial interstitial pathway.

\section{ACKNOWLEDGMENT}

We thank Mrs. Celia Cope, Department of Anatomy, St George's, for assistance with the Monastral blue photomicrography.

\section{REFERENCES}

1. Alexander JS, Hechtman HB, Shepro D. (1988). Phalloidin enhances barrier function and reduces inflammatory permeability in vitro. Microvasc Res 35: 308-315.

2. Asari A, Kuriyama S, Kuminami E, Uchiyama Y.
(1995). Cytochemical localization of hyaluronic acid in human synovium with special reference to its possible process of degradation. Arch Histol Cytol 58:6576.

3. Baldwin A, Thurston G. (1995). Changes in endothelial actin cytoskeleton in venules with time after histamine treatment. Am J Physiol 269:H1528-H1537.

4. Bentzel CH, Hainau B, Ho SW, Hui A, Edelman T, Anagnostopoulos T, Beneditt EL. (1980). Cytoplasmic regulation of tight junction permeability: effect of plant cytokines. Am J Physiol 239:C75-C89.

5. Berg A, Rubin K, Reed RK. (2001). Cytochalasin D induces oedema formation and lowering of interstitial fluid pressure in rat dermis. Am J Physiol 281:H7H13.

6. Bert JL, Martinez M. (1995). Interstitial fluid transport. In: Interstitium, Connective Tissue and Lymphatics. (RK Reed, NG McHale, JL Bert, CP Winlove, GA, Eds.) Portland Press, Laine, London. 101-117.

7. Cambridge H, Brain SD. (1992). Calcitonin generelated peptide increases blood flow and potentiates plasma protein extravasation in the rat knee joint. Brit J Pharmacol 106:746-750.

8. Clough G, Michel CC. (1988). The ultrastructure of frog microvessels following perfusion with the ionophore A23187. Q J Exp Physiol 73:123-125.

9. Clough G, Michel CC, Phillips ME. (1988). Inflammatory changes in permeability and ultrastructure of single vessels in the frog mesenteric circulation. $J$ Physiol 395:99-114.

10. Coleman PJ, Scott D, Mason RM, Levick JR. (1999). Characterization of the effect of high molecular weight hyaluronan on trans-synovial flow in rabbit knees. J Physiol 514:265-282.

11. Coué M, Brenner SL, Spector I, Korn ED. (1987). Inhibition of actin polymerization by latrunculin A. FEBS Lett 213:316-318.

12. Dejana E, Corada M, Lampugnani MG. (1995). Endothelial cell-to-cell junctions. FASEB J 9:910-918.

13. Edlund T. (1949). Studies on the absorption of colloids and fluid from rabbit knee joints. Acta Physiol Scand 18 Suppl 62:1-108.

14. Edwards JCW. (1999). The biology of synovial cells. In: Biology of the Synovial Joint. (CW Archer, B Caterson, M Benjamin, JR Ralphs, Eds.) Harwood Academic Publishers, Amsterdam. 225-233.

15. Ehringer WD, Yamany S, Steier K, Farag A, Roisen FJ, Dozier A, Miller FN. (1999). Quantitative image analysis of F-actin in endothelial cells. Microcirculation 6:291-303.

16. Ermert L, Bruckner H, Walmrath D, Grimminger F, Aktories K, Suttorp N, Duncker HR, Seeger W. (1995). Role of endothelial cytoskeleton in highpermeability edema due to botulinum C2 toxin in perfused rabbit lungs. Am J Physiol 268: L753-L761.

17. Feng D, Nagy JA, Pye K, Haramel I, Dvorak HF, Dvorak AM. (1999). Pathways of macromolecular extravasation across microvascular endothelium in re- 
sponse to VPF/VEGF and other vasoactive mediators. Microcirculation 6:23-44.

18. Hardy J, Bertone AL, Muir WW. (1998). Local hemodynamics, permeability and oxygen metabolism during acute inflammation of innervated or denervated isolated equine joints. Am J Vet Res 59:1307-1316.

19. Haselton FR, Mueller SN, Howell RE, Levine EM, Fishman AP. (1989). Chromatographic demonstration of reversible changes in endothelial permeability. J App Physiol 67:2032-2048.

20. Henderson KJ, Pitsillides AA, Edwards JCW, Worrall JG. (1993). Reduced expression of CD44 in rheumatoid synovial cells. Br J Rheumatol 32: Suppl 1:25.

21. Joris I, DeGirolami U, Wortham K, Majno G. (1982). Vascular labelling with Monastral Blue B. Stain Technology 57:177-183.

22. Kevil CG, Okayam N, Trocha SD, Kalogeris TJ, Coe LL, Specian RD, Davis CP, Alexander JS. (1998). Expression of zonula occudens and adherens junctional proteins in human venous and arterial endothelial cells: role of occludin in endothelial solute barriers. Microcirculation 5:197-210.

23. Knight AD, Levick JR. (1982). Pressure-volume relationships above and below atmospheric pressure in the synovial cavity of the rabbit knee. J Physiol 328: $403-420$.

24. Knight AD, Levick JR. (1985). Effects of fluid pressure on the hydraulic conductance of interstitium and fenestrated endothelium in the rabbit knee. J Physiol 360:311-332.

25. Knight AD, Levick JR, McDonald JN. (1988). Relation between trans-synovial flow and plasma colloid osmotic pressure, with an estimation of the albumin reflection coefficient in the rabbit knee. QJ Exp Physiol 73:47-65.

26. Knudson CB, Nofal GA, Pamintuan L, Aguiar DJ. (1999). The chondrocyte pericellular matrix: a model for hyaluronan-mediated cell-matrix interactions. Biochem Soc Trans 27:142-147.

27. Korthuis RJ, Carden DL, Kvietys PR, Shepro D, Fuseler J. (1991). Phalloidin attenuates postischemic neutrophil infiltration and increased microvascular permeability. J Appl Physiol 71:1261-1269.

28. Lacy BE, Underhill CB. (1985). The hyaluronate receptor is associated with actin filaments. J Cell Biol 105:1395-1404.

29. Levick JR. (1980). Contributions of the lymphatic and microvascular systems to fluid absorption from the synovial cavity of the rabbit knee. J Physiol 306: $455-461$.

30. Levick JR, McDonald JN. (1989). Ultrastructure of transport pathways in stressed synovium of the knee in anaesthetized rabbits. J Physiol 419:493-508.

31. Levick JR, Michel CC. (1973). The permeability of individually perfused frog mesenteric capillaries to T1824 and T1824-albumin as evidence for a large pore system. Q J Exp Physiol 58:67-85.

32. Levick JR, Price FM, Mason RM. (1996). Synovial matrix-synovial fluid system of joints. In: Extracellular Matrix, Volume 1, Tissue Function. (WD Comper, Ed.) Amsterdam, Harwood Academic Publishers. 328-377.

33. Lim MJ, Chiang ET, Hechtman HB, Shepro D. (2001). Inflammation-induced subcellular redistribution of VE-cadherin, actin and g-catenin in cultured human lung microvessel endothelial cells. $\mathrm{Mi}$ crovasc Res 62:366-382.

34. Madara J, Barenberg D, Carlson S. (1986). Effect of cytochalasin D on occluding junctions of intestinal absorptive cells: further evidence that the cytoskeleton may influence paracellular permeability and junctional charge selectivity. J Cell Biol 102:2125-2136.

35. McDonald DM, Thurston G, Baluk P. (1999). Endothelial gaps as sites for plasma leakage in inflammation. Microcirculation 6:7-22.

36. Michel CG, Kendall S. (1997). Differing effects of histamine and serotonin on microvascular permeability in anaesthetized rats. J Physiol 501:657-662.

37. Michel CC, Neal CR. (1999). Openings through endothelial cells associated with increased microvascular permeability. Microcirculation 6:45-54.

38. Parving H-H, Jensen HA, Westrup M. (1977). Increased transcapillary escape rate of albumin and IgG in essential hypertension. Scand J Clin Lab Invest 37:223-227.

39. Pierce PA, Xie G-X, Peroutka SJ, Green PA, Levine JD. (1995). 5-hydroxytryptamine-induced synovial plasma extravasation is mediated via 5-hydroxytryptamine $2 \mathrm{~A}$ receptors on sympathetic efferent terminals. J Pharmacol Exp Therapeutics 275:502-508.

40. Poli A, Scott D, Bertin K, Miserocchi G, Mason RM, Levick JR. (2001). Influence of actin cytoskeleton on intra-articular and interstitial fluid pressure in synovial joints. Microvasc Res 62:293-305.

41. Price FM, Levick JR, Mason RM. (1996). Changes in glycosaminoglycan concentration and synovial permeability at raised intra-articular pressures in rabbit knees. J Physiol 495:821-833.

42. Rassat J, Robenek H, Themann H. (1982). Cytochalasin B affects the gap and tight junctions of mouse hepatocytes. J Submicrosc Cytol 14:427-439.

43. Reed RK, Woie K, Rubin K. (1997). Integrins and control of interstitial pressure. News Physiol Sci 12: 42-48.

44. Ribeiro CMP, Reece J, Putney JW. (1997). Role of the cytoskeleton in calcium signalling in NIH 3 T3 cells. An intact cytoskeleton is required for agonist-induced $\left[\mathrm{Ca}^{2+}\right]$ signalling, but not for capacitative calcium entry. J Biol Chem 272:26555-26561.

45. Rinaldi N, SchwarzEywill M, Weiss D, LeppepmannJansen P, Lukoschek M, Keilholz U, Barth TFE. (1997). Increased expression of integrins on fibroblast-like synoviocytes from rheumatoid arthritis in vitro correlates with enhanced binding to extracellular matrix proteins. Ann Rheum Dis 56:45-51.

45b Scott D, Bertin K. Poli A, Levick JR, Miserocchi GA. 
(2001). Interstitial pressure gradients around joints; location of chief resistance to fluid drainage from the rabbit knee. Exp Physiol 86:739-747.

46. Shasby DM, Shasby SS, Sullivan JM, Peach MJ. (1982). Role of endothelial cell cytoskeleton in control of endothelial permeability. Circ Res 51:657-661.

47. Spector I, Shocket NR, Kashman Y, Groweiss A. (1983). Latrunculins: novel marine toxins that disrupt microfilament organization in cultured cells. Science 219:493-495.

48. Symons MH, Mitchison TJ. (1991). Control of actin polymerization in live and permeabilised fibroblasts. J Cell Biol 114:503-513.
49. Takenaga K, Olden K, Yamada KM. (1990). Analysis of the interaction between the fibronectin receptor and cytoskeletal proteins in human fibroblasts. A chemical crosslinking study. J Cell Biol 111:299a.

50. Unemori EN, Werb Z. (1986). Reorganization of polymerized actin: a possible trigger for induction of procollagenase in fibroblasts cultured in and on collagen gels. J Cell Biol 103:1021-1031.

51. Wallis WJ, Simkin PA, Nelp WB. (1987). Protein traffic in human synovial effusions. Arthritis Rheum 30:57-63.

52. Wang N. (1998). Mechanical interactions among cytoskeletal filaments. Hypertension 32:162-165. 